\title{
Demographic and Cognitive Factors in Teachers' Perception of Curriculum Innovations in Enugu State, Nigeria
}

\author{
Chidiebere. R. Onyia, Ph.D \\ Department of Art Education, Faculty of Education, University of Nigeria Nsukka Campus \\ Email: chidiebere.onyia@unn.edu.ng
}

\author{
Obiamaka Egbo, Ph.D \\ Department of Banking and Finance, Faculty of Business Administration, University of Nigeria, Enugu Campus \\ Email: obiamaka.egbo@unn.edu.ng \\ Nkechi Onyeneho, Ph.D \\ Department of Social Work, Faculty of Social Sciences, University of Nigeria Nsukka Campus \\ Email:nkechi.onyeneho@unn.edu.ng
}

\section{Doi:10.5901/mjss.2016.v7n2p331}

\section{Abstract}

Globally, education systems continue to explore ways of designing effective curriculum innovation changes across subject areas. This has been the case in Nigeria where the curriculum change process has historically excluded teacher input in the thinking and designing of the curriculum. This paper explores teachers' perceptions of these efforts and the demographic and cognitive factors that shape their perceptions. A structured interview schedule was administered to 205 teachers purposively selected from six educational zones in Enugu State. The results revealed that teachers' perceptions of curriculum innovation were affected by abysmal performance of past curriculum policies designed and implemented in Nigeria.

Keywords: Curriculum change; Curriculum innovation; Demographic and cognitive factors; Teachers' perception; Teacher knowledge and inclusion; professional development.

\section{Introduction}

Education reformers in developing nation continue to explore innovation in curriculum as an important component of the change process and this is why it is very crucial to understanding how these innovations can be confirmed. With transformation in the global economic and technological realities many countries have had to change their curricula to enhance the production of graduate that fit the $21^{\text {st }}$ century societal needs and to keep pace with the increasingly market driven economy. Nigeria is no exception. Recently, the Federal Ministry of Education in Nigeria embarked on a curriculum review to make school curriculum more responsive to the demands of contemporary times. The main objective of this study is to explore teacher's perception on their input designing curriculum which includes the demographic and cognitive factors that shape them.

However, the implication of curriculum goes beyond just curriculum design issues. It extends to teaching, learning, administration and the culture of the school (Shao and Bruening, 2005). According to Reed (2000), significant change in curriculum command ardent attention of the school community and the full range of school personnel. It is universally accepted in many parts of the world that the teacher, for instance, is pivotal in any change within the school system. Teachers are germane to the success of educational reform efforts and are the key link in any improvement and reform process (Gordon and Yocke, 1999). Researchers have identified that teachers have increasingly been considered the centerpiece of educational change rather than mere executors of policies enforced on them (Duke, 2004 and Datnow, Hubbard \& Mehan, 2002). According to Charalambous and Philippou (2010) attention has now been given to teachers' personal characteristics and capacities that could affect curriculum reform implementations. 


\subsection{Teacher perception and knowledge of curriculum}

Teachers are the final decision makers on the policies they chose to implement and the educational leaders they decide to tag along (Shao and Bruening, 2005). It follows therefore that teachers' perception of the curriculum should be considered a crucial element in ensuring the successful implementation of a new curriculum. The perceptions are held to be influenced by what they know and their background. Therefore, Reed (2000) posits that teachers need to be intimately involved in the conceptualization and direction of innovations in the school curriculum. This implies that the system of teacher-isolation must give way to a shared decision making process. Isolationism must give way to knowledge sharing among teachers, their leaders and policymakers. Teacher-knowledge should be subsumed within the process of change. Fine and Raack (2012), in analysis of the failure of educational research and best practices in classroom instructional improvements and student achievement, noted that the teacher is often taken for granted and sometimes overlooked for reasons that border on lack of professionalism. In other words, most systems lack the requisite professional development protocol to drive an effective professional development system which should translate research into classroom practice. In the event of a system failure therefore, it is more often than not attributable to failure in providing the teachers with opportunities for concurrent professional development to acquire, reflect upon and apply new techniques in a constantly changing and globalized educational system. Bransford et al. (2005) as cited in King-Sang Chan (2010).

\subsection{Teacher Inclusion in curriculum change}

Teacher participation in policy development in Nigeria is still at the beginning stages, especially with the role of teachers being highlighted only during the implementation phase and not during the thinking, design and developmental phases. Teachers' involvement in implementation of curriculum materials have been with mixed results (Roehrig and Kruse, 2005) leading to scholars asking questions of the role of teacher-inclusion at early stages of curriculum reform process. van Driel, Astrid and Verloop (2008) reiterates the need for teacher-inclusion. In studying science education, these scholars noted that, science education clearly demonstrated that the influence of the teacher outweighs that of such other factors as the content of the curriculum and extra-curricular activities (Osborne et al. 2003). Historically, teacher role in curriculum change has been perceived as 'executing' the innovative ideas of others (such as policy-makers and curriculum designers). In contemporary times, there is a consensus in literature that the reform or actual practice should be in the hands of the professional sector (Ball and Cohen 1999, van Driel and Verlop, 2008). These studies conclude that the school system and the teachers should be allowed more freedom to participate in the planning and execution of their own teaching, especially when the collective success of the programme or curriculum is measured by their intervention. To that effect, teachers' commitment to, and ownership of curriculum change will increasingly affect the overall performance of students in learning the innovation integrated in the curriculum regardless of the discipline.

In every change process, there are barriers that affect effective implementation and consequently hinder overall performance. To understand these barriers to curriculum change, certain historical challenges to education reform should be addressed. For instance traditional methods of curriculum implementation, teacher-centered beliefs, and values of all constituents involved (administrators, teachers, students, parents, etc.), teachers' knowledge bases and personal characteristics (i.e., age, experience, academic training), and the traditional organizational structure of schools (Anderson, 1996; Cuban, 1995, Fullan, 2001). Although these factors have been identified over the years, policy makers in Nigeria are yet to fully integrate component of each factor, especially, teachers' roles and beliefs into the curriculum change process.

\subsection{Curriculum Reform}

According to Flouris and Pasia (2003) "curriculum reform deals with concrete didactical and pedagogical issues: teaching and learning, involving subject contents, didactics, pedagogical development, and evaluation." Curriculum reform clearly revolves around making educational choices that will impact the greatest value to all learners in the school system. This requires considering the different structures of the processes, to decide who is responsible for these processes, to choose aims, and to estimate the different future outcomes (Macdonald 2003). The implementation of these processes also plays a major role in curriculum reforms (Seikkula-Leino, 2011).

In discussing curriculum reform, certain factors if not addressed could affect teachers' adoption of innovative curriculum. Cuban (1993) noted time constraint as a key issue pointing out that changes in classroom traditions, engendering movement from teacher-centeredness to student-centeredness impose a direct and inexorable commitment upon the teacher to invest far more time and effort than is the case in the teacher-centered tradition. In addition to the 
issue of time, Erickson (2001) noted curriculum understanding and instruction as critical points for educational change. The goal of pursuing quality education in line with changing social and economic demands cannot be realized without making allowance for professional dialogue, training of staff and curriculum development. According to Shao and Bruening (2005) teachers deserve quality planning time to develop effective curriculum outlines that permits them to raise intellectual and academic standards that will meet the needs of the market driven economies. Similarly, Pierce (1981) listed support of administration as one of the three factors attributed to a teacher's attitude towards innovative practices. He noted that those who had administrative support were more likely to adopt changes and innovations in their teaching.

While these arguments hold strong even for Nigeria, it is yet not clear how the disciplinary cluster experiences impact on teachers' perception of the new curriculum in Nigeria. Teachers with different backgrounds, namely civic education, entrepreneurship, information and communication technology as well as culture and creative arts were recently requested to express their perceptions of the new school curriculum in Nigeria. This paper therefore describes the demographic and cognitive factors that influence teachers' perceptions of the new curriculum in Nigeria

\section{Method and Procedures}

The study was located in Enugu State. Enugu State is divided into six educational zones, namely Agbani, Awgu, Enugu, Nsukka, Obollo-Afor and Udi with secondary schools numbering over 285 and a total student and teacher populations of over 156,800 and 2850 respectively. A cross sectional design was employed in the study, with the teachers in the different subject areas as the unit of analysis. The cross-sectional survey was employed to examine factors that are associated with a particular characteristic of interest which is the subject area. The population for the study included public and private post primary school teachers in the 17 local government areas (LGAs) of Enugu State, Nigeria, who participated in the training on four modules on the new school curriculum. The target populations were teachers involved in the teaching of civic education, information \& communication technology, culture \& creative arts as well as entrepreneurship. The teachers were purposively nominated from their various institutions to participate in the one day training exercise. All the participants at the training took part in the assessment, which took place before the lectures commenced.

A survey questionnaire was constructed for data collection. The questionnaire was in five sections. The first section collected information on the socio-demographic characteristics of the participating teachers. The other four sections addressed the different issues in the new curriculum, namely, organizing subject matter for presentation to students; organizing the students' practice of the intellectual modes and abilities; organizing student curriculum to enhance student intellectual development and finally, teacher support for the effective curriculum implementation and evaluation. The perceptions of the teachers on these five issues were garnered with the instrument. A five-point Likert scale was used to measure the respondents' perceptions: 1-strongly agree; 2=agree; 3=somewhat; 4=disagree; 5=strongly disagree. A section, with open ended questions was also devoted to gauging their opinion on issues relating the implementation of the new curriculum. Two hundred and five survey questionnaires were issued to the participating teachers. All the questionnaires were validly completed and included in the analysis that follows below.

\subsection{Socio-Demographic Characteristics of the Respondents}

The sex distribution of the respondents follows the trend in many Nigerian communities where there are slightly more women than men in the population. The sample consisted of $50.7 \%$ and $49.3 \%$ women and men respectively. Slightly more than half (56.6\%) teach at the Senior Secondary School (SSS) level).

The respondents were almost evenly distributed across the different disciplinary specialties implicated in the curriculum design and evaluation. Civic education and entrepreneurship however constituted slight more (28.3\% and $29.8 \%$ ) respectively. Two-thirds of the respondents were from rural local government areas (LGAs) (66.3\%). Almost twothirds $(60 \%)$ of all the respondents had been teaching for more than 10 years. A large proportion (96.6\%) consisted of teachers in public schools. Also two-thirds of the respondent had university degrees.

\section{Findings}

\subsection{Perception on Organizing Subject Matter for Presentation to Students}

More than eighty percent (81.5\%) of the respondents strongly agreed that they arrange the concepts and principles in sequence from simple to complex. Smaller proportions of the respondent seem to only agree or even disagree with each 
of the prompts on this issue. The details are contained in Table A.1.

Table A.1: Distribution of Respondents by Tendency to Organize Subject Matter for Presentation to Students (\% in Parenthesis)

\begin{tabular}{|c|c|c|c|c|c|}
\hline \multirow[t]{2}{*}{ Organizing Subject Matter } & \multicolumn{5}{|c|}{ Tendency } \\
\hline & 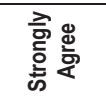 & 浐 & 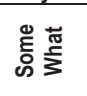 & 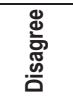 & 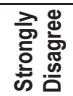 \\
\hline $\begin{array}{l}\text { I identify specific concepts and principles that students must learn before classroom curriculum } \\
\text { design }\end{array}$ & $127(62.6)$ & $62(30.2)$ & $2(1.0)$ & $9(4.4)$ & $3(1.5)$ \\
\hline I arrange the concepts and principles in sequence from simple to complex & $167(81.5)$ & $36(17.6)$ & $1(0.5)$ & $0(0.0)$ & $1(0.5)$ \\
\hline I present organizers such as verbal, visual and concrete illustrations to support student learning & $125(61.0)$ & $69(33.7)$ & $7(3.4)$ & $2(1.0)$ & $2(1.0)$ \\
\hline $\begin{array}{l}\text { I review the whole subject matter curriculum at the beginning of the year (or term) to identify } \\
\text { main ideas that will lead to transferable knowledge and skills }\end{array}$ & $105(52.0)$ & $73(36.1)$ & $17(8.4)$ & $7(3.5)$ & $0(0.0)$ \\
\hline I review prior year students; performance to guide subject matter curriculum organization & $83(41.1)$ & $97(48.0)$ & $14(6.9)$ & $8(4.0)$ & $0(0.0)$ \\
\hline
\end{tabular}

To assess the respondents' overall performance on the prompts, a score index was constructed. In view of the fact that the data seemed skewed towards agreement, those who strongly agreed were assumed to have no reservation in their agreement and scored ' 1 '. On the other hand, those who only agreed or disagreed at any level were classified as not truly agreed and scored ' 0 '. The results were cumulated to get an index. The respondents' performance ranged from 0 to 5 points with a mean score of $3.0(3.0 \pm 1.31 \mathrm{SD})$.

The median score was 3.0 irrespective of the classification of the teachers. There were wider variations among those in civic education and culture \& creative arts with scores ranging from 0 to 5 points, than those in the ICT group. The scores among the ICT teachers ranged from 2 to 5 point though with some outliers as low as 0 point. The performance index on organizing subjects matter for presentation to students was further regrouped into low $(<4)$ and high (4+). The mean of 3.0 point was used as the cut-off point. The high score was compared across selected demographic variables. The results are contained in Table A.2.

Table A.2: Distribution of Respondents by Demographic, Cognitive (Learning Group) Characteristics, and High Score on Organizing Subject Matter for Presentation to Students

\begin{tabular}{|c|c|c|c|c|}
\hline \multicolumn{2}{|c|}{ Demographic Characteristics Categories } & \multicolumn{2}{|c|}{$\begin{array}{c}\text { Number } \% \text { High Score } \\
\geq 4 \text { points }\end{array}$} & \multirow[t]{2}{*}{$\begin{array}{c}X^{2} \\
P \text { value } \\
\end{array}$} \\
\hline \multirow[t]{4}{*}{ Learning Group } & Civic education & 58 & 67.2 & \\
\hline & Entrepreneurship & 61 & 60.7 & 3.017 \\
\hline & Culture and creative arts & 43 & 65.1 & 0.389 \\
\hline & Information \& Comm. Technology (ICT) & 43 & 76.6 & \\
\hline \multirow{2}{*}{ Level } & Junior Secondary School (JSS) & 89 & 57.3 & 6.438 \\
\hline & Senior Secondary School (SSS) & 116 & 74.1 & 0.009 \\
\hline \multirow[t]{2}{*}{ School Type } & Public & 198 & 66.2 & 1.273 \\
\hline & Private & 7 & 83.3 & 0.529 \\
\hline \multirow[t]{3}{*}{ Years of Experience } & $<6$ Years & 46 & 54.3 & \multirow{3}{*}{$\begin{array}{l}7.245 \\
0.027\end{array}$} \\
\hline & 6-10 Years & 36 & 58.3 & \\
\hline & $>10$ Years & 123 & 74.0 & \\
\hline \multirow[t]{2}{*}{ Sex } & Male & 101 & 64.4 & 0.549 \\
\hline & Female & 104 & 69.2 & 0.277 \\
\hline \multirow[t]{5}{*}{ Qualification } & NCE & 48 & 37.5 & \multirow{5}{*}{$\begin{array}{l}31.891 \\
<0.001\end{array}$} \\
\hline & $\mathrm{BSc}$ & 131 & 75.6 & \\
\hline & MSc & 17 & 94.1 & \\
\hline & $\mathrm{PhD}$ & 1 & 0.0 & \\
\hline & Other (PGDE) & 8 & 50.0 & \\
\hline \multirow[t]{2}{*}{ Locality } & Urban LGA & 69 & 71.0 & 0.822 \\
\hline & Rural LGA & 136 & 64.7 & 0.228 \\
\hline
\end{tabular}

Table A.2 shows that more of the respondents in the ICT and civic education groups score high on this issue. All the 
same, there was no statistical difference among the different disciplinary classifications. Similarly, the sex, locality and school type of the respondent did not make a difference with regards to teachers' perception of organization of subject matter for presentation to students as a necessity. However, other factors including level where they teach, years of experience and qualification of the teachers were statistically significant. The more qualified, longer serving teachers, who teach in SSS were more perceptive of the need to organize subject matter for presentation to students.

\subsection{Perception on Organizing the Students' Practice of the Intellectual Modes and Abilities}

In response to questions on their perceptions on organizing the students' practice of the intellectual mode and abilities, the respondents generally agreed strongly with the prompts. Slightly more and less than fifty percent $(54.9 \%$ and $45.1 \%)$ agreed strongly to the prompts about identification of specific modes and abilities the students will practice and integrating these specific modes and abilities within subject matter respectively. Very small proportions disagreed. The details are contained in Table A.3.

Table A.3: Distribution of Respondents by Tendency to Organize the Students' Practice of the Intellectual Modes and Abilities (\% in Parenthesis)

\begin{tabular}{|c|c|c|c|c|c|}
\hline \multirow[b]{2}{*}{ Organize the Students' Practice of the Intellectual Modes and Abilities } & \multicolumn{5}{|c|}{ Tendency } \\
\hline & 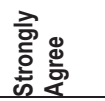 & ষ্ঠু & 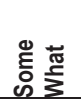 & 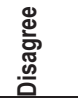 & 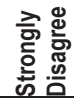 \\
\hline I identify the specific modes and abilities the student will practice to facilitate learning & $112(54.9)$ & $80(39.2)$ & $9(4.4)$ & $2(1.0)$ & $1(0.5)$ \\
\hline I integrate these specific modes and abilities within subject matter curriculum implementation & $92(45.1)$ & $97(47.5)$ & $14(6.9)$ & $1(0.5)$ & $0(0.0)$ \\
\hline
\end{tabular}

To assess the respondents' overall performance on the prompts, a score index was constructed. In view of the fact that the data seemed skewed towards agreement, those who strongly agreed were assumed to have no reservation in their agreement and scored ' 1 '. On the other hand, those who only agreed or disagreed at any level were classified as not truly agreed and scored ' 0 '. The results were cumulated to get an index. The respondents' performance ranged from 0 to 2 points with a mean score of $0.995(0.995 \pm 0.843 S D)$.

The median score was 1.0 irrespective of the classification of the teachers. All the same variations are observed in terms of the level of dispersion in the within group performance. For instance, there were wider variations among those in civic education, entrepreneurship and the ICT groups, the culture \& creative arts group converged mainly between 0.5 and 2.0 points. Only $25 \%$ of those in the culture and creative arts group scored between 0.0 and 0.5 points on their perceptions.

The performance index on organizing subjects matter for presentation to students was further regrouped into low $(<1.0)$ and high $(\geq 1.0)$. The mean of 1.0 point was used as the cut-off point. The high score was compared across selected demographic variables. The results are contained in Table A.4.

Table A.4: Distribution of Respondents by Demographic, Cognitive Characteristics and High Score on Organizing the Students' Practice of the Intellectual Modes Abilities

\begin{tabular}{llccc}
\hline Demographic Characteristics & Categories & Number & $\begin{array}{c}\text { \% High Score } \\
\geq 1 \text { points }\end{array}$ & $\begin{array}{c}X^{2} ; \\
\mathrm{P} \text { value }\end{array}$ \\
\hline Learning Group & Civic education & 58 & 60.3 & 2.465 \\
& Entrepreneurship & 61 & 62.3 & 0.482 \\
& Culture and creative arts & 43 & 74.4 & \\
& Information \& Comm. Technology (ICT) & 43 & 62.8 & \\
\hline Level & Junior Secondary School (JSS) & 89 & 61.8 & 0.461 \\
& Senior Secondary School (SSS) & 116 & 66.4 & 0.297 \\
\hline School Type & Public & 198 & 63.6 & 1.541 \\
& Private & 7 & 83.3 & 0.463 \\
\hline Years of Experience & < Y Years & 46 & 71.7 & 3.410 \\
& 6-10 Years & 36 & 72.2 & 0.182 \\
\hline & $>10$ Years & 123 & 59.3 & \\
\hline
\end{tabular}




\begin{tabular}{llccc}
\hline Sex & Male & 101 & 65.3 & 0.79 \\
& Female & 104 & 63.5 & 0.446 \\
\hline Qualification & NCE & 48 & 70.8 & \\
& BSc & 131 & 61.1 & 5.172 \\
& MSc & 17 & 64.7 & 0.270 \\
& PhD & 1 & 0.0 & \\
\hline Locality & Other (PGDE) & 8 & 50.0 & \\
& Urban LGA & 69 & 63.8 & 0.018 \\
& Rural LGA & 136 & 64.7 & 0.507 \\
\hline
\end{tabular}

Table A.4 shows that more of the respondents in the culture \& creative arts group (74.4\%) than others scored high on this issue. The ICT and entrepreneurial groups followed this with $62.8 \%$ and $62.3 \%$ respectively. All the same, there was no statistical difference among the different disciplinary classifications, indicating no difference among the groups, all of which contributed majorly to the high perception scores. Similarly, there were no differences in sex, locality and school type of the respondent with regards to teachers' perception of organization of subject matter for presentation to students as a necessity. All the same, in percentage points, beginning teachers to the profession; in the entrepreneurial group, teaching the senior secondary students, among others contributed more to the perception score of 1.0 point and above.

\subsection{Organize Student Curriculum to Enhance Student Intellectual Development}

The respondents had a series of 19 prompts to text their perceptions regarding the key curriculum concept of 'organizing student curriculum to enhance student intellectual development'. The prompts covered issues of providing guidance for students' learning; provision of practical exercises; evaluation and feedback; motivation as well as individualization. With the exception of a few cases, the respondents' strong agreement with each prompt revolved around $50.0 \%$.

On individualization, for instance, only $37.1 \%$ of the respondents strongly agreed to the prompt, which sought to know their perception on providing for students who learn at different rates in my curriculum instructional design (lesson planning and lesson delivery). Similarly, 38.2\% strongly agreed with the prompt, which assessed their perception on providing enrichment learning activities for fast learners in my curriculum instructional design. The details are contained in Table A.5.

Table A.5: Distribution of Respondents by Tendency to Organize Student Curriculum to Enhance Student Intellectual Development (\% in Parenthesis)

\begin{tabular}{|c|c|c|c|c|c|}
\hline \multirow[b]{2}{*}{ Organizing Student Curriculum to Enhance Student Intellectual Development } & \multicolumn{5}{|c|}{ Tendency } \\
\hline & 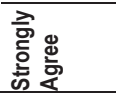 & 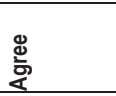 & 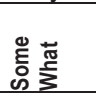 & 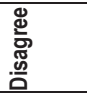 & 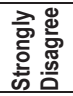 \\
\hline \multicolumn{6}{|l|}{ I provide for practice by: } \\
\hline $\begin{array}{l}\text { Demonstrating or modeling or providing situations in which the student can experiment } \\
\text { and/or discover the desired behavior }\end{array}$ & $113(55.1)$ & $81(39.5)$ & $9(4.4)$ & $2(1.0)$ & $0(0.0)$ \\
\hline Supervising the student's initial trial of concept & $95(47.0)$ & $97(48.0)$ & $9(4.5)$ & $1(0.5)$ & $0(0.0)$ \\
\hline $\begin{array}{l}\text { Gradually withdrawing initially necessary prompts after student has shown ability or } \\
\text { competence }\end{array}$ & $52(26.8)$ & $99(51.0)$ & $21(10.8)$ & $18(9.3)$ & $4(2.1)$ \\
\hline $\begin{array}{l}\text { Describing to students the intellectual modes and abilities involved in their work and relate } \\
\text { to specific learning activities }\end{array}$ & $110(53.9)$ & $81(39.7)$ & $8(3.9)$ & $4(2.0)$ & $1(0.5)$ \\
\hline Helping students learn to evaluate their performance & $121(59.0)$ & $68(33.8)$ & $8(4.0)$ & $4(2.0)$ & $0(0.0)$ \\
\hline \multicolumn{6}{|l|}{ I provide for practice by: } \\
\hline Ensuring that students are active during the learning process & $169(82.8)$ & $34(16.7)$ & $0(0.0)$ & $1(0.5)$ & $0(0.0)$ \\
\hline Pacing their (students') work based on learning feedback & $90(44.1)$ & $100(49.0)$ & $8(3.9)$ & $6(2.9)$ & $0(0.0)$ \\
\hline $\begin{array}{l}\text { Varying the instructional context to provide multiple opportunities for mastery of leading } \\
\text { objective(s) }\end{array}$ & $108(53.7)$ & $84(41.8)$ & $8(4.0)$ & $1(0.5)$ & $0(0.0)$ \\
\hline \multicolumn{6}{|l|}{ I evaluate and provide feedback by: } \\
\hline Reinforcing correct responses & $142(70.0)$ & $58(28.6)$ & $0(0.0)$ & $3(1.5)$ & $0(0.0)$ \\
\hline Correcting inadequate responses appropriately & $128(63.4)$ & $71(35.1)$ & $1(0.5)$ & $2(1.0)$ & $0(0.0)$ \\
\hline Informing students with diagnostic feedback about their performance (formative) & $95(46.8)$ & $98(48.3)$ & $7(3.4)$ & $1(0.5)$ & $2(1.0)$ \\
\hline $\begin{array}{l}\text { Determining if student has mastered stated subject matter objectives and is ready to move } \\
\text { on (summative) }\end{array}$ & $113(55.1)$ & $88(42.9)$ & $4(2.0)$ & $0(0.0)$ & $0(0.0)$ \\
\hline \multicolumn{6}{|l|}{ Motivate } \\
\hline I encourage students to cultivate the desired behavior for lifelong learning & $145(70.7)$ & $59(28.8)$ & $1(0.5)$ & $0(0.0)$ & $0(0.0)$ \\
\hline
\end{tabular}




\begin{tabular}{|c|c|c|c|c|c|}
\hline \multirow[b]{2}{*}{ Organizing Student Curriculum to Enhance Student Intellectual Development } & \multicolumn{5}{|c|}{ Tendency } \\
\hline & 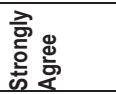 & ฏ & 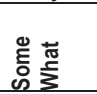 & 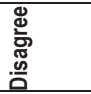 & 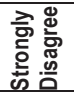 \\
\hline $\begin{array}{l}\text { I show students the value of learning the concepts and principles to be taught (in the } \\
\text { subject) by showing their relevance to meaningful work }\end{array}$ & $114(55.6)$ & $59(28.8)$ & $1(0.5)$ & $0(0.0)$ & $0(0.0)$ \\
\hline I help students achieve success & $144(71.3)$ & $51(25.2)$ & $6(3.0)$ & $1(0.5)$ & $0(0.0)$ \\
\hline \multicolumn{6}{|l|}{ Individualize } \\
\hline $\begin{array}{l}\text { I provide for students who learn at different rates in my curriculum instructional design } \\
\text { (lesson planning and lesson delivery) }\end{array}$ & $76(37.1)$ & $88(42.9)$ & $23(11.2)$ & $18(8.8)$ & $0(0.0)$ \\
\hline I provide enrichment learning activities for fast learners in my curriculum instructional design & $78(38.2)$ & $89(43.6)$ & $22(10.8)$ & $13(6.4)$ & $2(1.0)$ \\
\hline I provide opportunities for extra help for slow learners in my curriculum instructional design & $92(45.8)$ & $94(46.8)$ & $13(6.5)$ & $2(1.0)$ & $0(0.0)$ \\
\hline
\end{tabular}

To assess the respondents' overall performance on the prompts, a score index was constructed. In view of the fact that the data seemed skewed towards agreement, those who strongly agreed were assumed to have no reservation in their agreement and scored ' 1 '. On the other hand, those who only agreed or disagreed at any level were classified as not truly agreed and scored ' 0 '. The results were cumulated to get an index. The respondents' performance ranged from 0 to 18 points with a mean score of $9.68(9.68 \pm 4.17 S D)$.

The median score was 9.0 points in respect of those with Entrepreneurial, ICT and Civic education skills. It median score was slightly higher among those with Culture and creative arts skills (10.0 points). Variations were also observed in terms of the level of dispersion in the within group performance. For instance, there were wider variations among those in Entrepreneurship group (0-17) than other grouping. The Culture \& creative arts group converged mainly between 5 and 17 points on their perceptions.

The performance index on organizing subjects matter for presentation to students was further regrouped into low $(<10.0)$ and high $(\geq 10.0)$. The mean of 9.6 point was used as the cut-off point. The high score was compared across selected demographic variables. The results are contained in Table A.6.

Table A.6: Distribution of Respondents by Demographic Characteristics and High Score on Organizing Student Curriculum to Enhance Student Intellectual Development

\begin{tabular}{llccc}
\hline \multirow{2}{*}{ Demographic Characteristics } & Categories & Number $\begin{array}{c}\text { High Score } \\
\geq 10 \text { points }\end{array}$ & $\begin{array}{c}X^{2} ; \\
\text { P value }\end{array}$ \\
\hline Learning Group & Civic education & 58 & 43.1 & \\
& Entrepreneurship & 61 & 47.5 & 2.293 \\
& Culture and creative arts & 43 & 58.1 & 0.514 \\
& Information \& Comm. Technology (ICT) & 43 & 48.8 & \\
\hline Level & Junior Secondary School (JSS) & 89 & 46.1 & 0.463 \\
& Senior Secondary School (SSS) & 116 & 50.9 & 0.295 \\
\hline School Type & Public & 198 & 49.0 & 1.626 \\
& Private & 7 & 33.3 & 0.443 \\
\hline Years of Experience & < Years & 46 & 54.3 & 3.057 \\
& 6-10 Years & 36 & 58.3 & 0.217 \\
& >10 Years & 123 & 43.9 & \\
\hline Sex & Male & 101 & 42.6 & 3.069 \\
& Female & 104 & 54.8 & 0.053 \\
\hline Qualification & NCE & 48 & 43.8 & \\
& BSc & 131 & 48.9 & 6.259 \\
& MSc & 17 & 47.1 & 0.181 \\
& PhD & 1 & 0.0 & \\
\hline Locality & Other (PGDE) & 8 & 87.5 & \\
& Urban LGA & 69 & 53.6 & 0.976 \\
& Rural LGA & 136 & 46.3 & 0.200 \\
\hline
\end{tabular}

Table A.6 shows that more of the respondents in the culture \& creative arts group (58.1\%) than others scored high on this issue. The ICT and entrepreneurial groups followed this with $48.8 \%$ and $45.7 \%$ respectively. All the same, there was no statistical difference among the different disciplinary classifications, indicating no difference among the groups, all of which contributed majorly to the high perception scores. Similarly, there were no differences in locality and school type of 
the respondent with regards to teachers' perception of organization of subject matter for presentation to students as a necessity. All the same, in percentage points, being fresher (beginning teachers) in the profession; in the entrepreneurial group, teaching the senior secondary students, among others contributed more to the high perception score of 10.0 point and above. It is also observed that the female teachers (54.8\%) more than their male counterparts (42.6\%) scored high $(p=0.053)$.

\subsection{Giving Support for Effective Curriculum Implementation and Evaluation}

The respondents had a series of 6 prompts to test their perceptions regarding the key curriculum concept of 'giving support for effective curriculum implementation and evaluation'. In response to prompts on being more effective as a teacher if targeted professional development is provided by the authorities, more than seventy percent (77.3\%) agreed strongly. Similarly more than half (55.1\%) strongly agreed that curriculum materials are made available so that teachers can become acquainted with the new materials and methods before advocating for use by responsible authorities (private and public). Smaller proportions of the respondent seem to only agree or even disagree with each of the prompts on this issue. The details are contained in Table A.7.

Table A.7: Distribution of Respondents by Tendency to Give Support for Effective Curriculum Implementation and Evaluation (\% in Parenthesis)

\begin{tabular}{|c|c|c|c|c|c|}
\hline \multirow[b]{2}{*}{ Give Support for Effective Curriculum Implementation and Evaluation } & \multicolumn{5}{|c|}{ Tendency } \\
\hline & 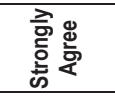 & ֻँ & 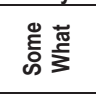 & 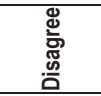 & 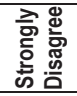 \\
\hline $\begin{array}{l}\text { Curriculum materials are made available so that teachers can become acquainted with the new } \\
\text { materials and methods before advocating for use by responsible authorities (private and public) }\end{array}$ & $113(55.1)$ & $49(23.9)$ & $12(5.9)$ & $23(11.2)$ & $8(3.9)$ \\
\hline $\begin{array}{l}\text { Teachers are given opportunity to work together with other teachers in the same grade level to } \\
\text { support teaching efficiency and professional growth }\end{array}$ & $73(35.6)$ & $63(30.7)$ & $26(12.7)$ & $36(17.6)$ & $7(3.4)$ \\
\hline $\begin{array}{l}\text { Curriculum training is provided at the beginning of the school year or term using evidence from } \\
\text { student achievement data }\end{array}$ & $65(31.7)$ & $61(29.8)$ & $22(10.7)$ & $45(22.0)$ & $12(5.9)$ \\
\hline $\begin{array}{l}\text { The school administrators set learning goals for students by grade level/subject each academic } \\
\text { year in collaboration with classroom teachers }\end{array}$ & $54(26.9)$ & $84(41.8)$ & $20(10.0)$ & $35(17.4)$ & $8(4.0)$ \\
\hline $\begin{array}{l}\text { School administrators provide resources that help teachers increase their content competence } \\
\text { and curriculum instructional abilities }\end{array}$ & $67(32.8)$ & $61(29.9)$ & $24(11.8)$ & $42(20.6)$ & $10(4.9)$ \\
\hline $\begin{array}{l}\text { I will be more effective as a teacher if targeted professional development is provided by the } \\
\text { authorities }\end{array}$ & $157(77.3)$ & $44(21.7)$ & $0(0.0)$ & $1(0.5)$ & $1(0.5)$ \\
\hline
\end{tabular}

To assess the respondents' overall performance on the prompts, a score index was constructed. In view of the fact that the data seemed skewed towards agreement, those who strongly agreed were assumed to have no reservation in their agreement and scored ' 1 '. On the other hand, those who only agreed or disagreed at any level were classified as not truly agreed and scored ' 0 '. The results were cumulated to get an index. The respondents' performance ranged from 0 to 6 points with a mean score of $2.58(2.58 \pm 1.74 \mathrm{SD})$.

The median score was 3.0 points in respect of those with Entrepreneurial and Civic education skills. On the other hand it was slightly lower (2.0 points) among those with Culture and creative arts as well as ICT skills. Variations were also observed in terms of the level of dispersion in the within group performance.

The performance index on organizing subjects matter for presentation to students was further regrouped into low $(<3.0)$ and high $(\geq 3.0)$. The mean of 2.58 points was used as the cut-off point. The high score was compared across selected demographic variables. The results are contained in Table A.8.

Table A.8: Distribution of Respondents by Demographic, Cognitive Characteristics and High Score on Give Support for Effective Curriculum Implementation and Evaluation

\begin{tabular}{llccc}
\hline Demographic Characteristics Categories & $\begin{array}{c}\text { Number } \begin{array}{c}\text { High Score } \\
\geq 3 \text { points }\end{array} \\
\end{array}$ & $\begin{array}{c}X^{2} ; \\
\text { P value }\end{array}$ \\
\hline Learning Group & Civic education & 58 & 56.9 & \\
& Entrepreneurship & 61 & 50.8 & 3.909 \\
& Culture and creative arts & 43 & 41.9 & 0.272 \\
& Information \& Comm. Technology (ICT) & 43 & 39.5 & \\
\hline
\end{tabular}




\begin{tabular}{llccc}
\hline Level & Junior Secondary School (JSS) & 89 & 46.1 & 0.312 \\
& Senior Secondary School (SSS) & 116 & 50.0 & 0.338 \\
\hline School Type & Public & 198 & 49.0 & 1.510 \\
& Private & 7 & 33.3 & 0.470 \\
\hline Years of Experience & $<6$ Years & 46 & 54.3 & 4.827 \\
& 6-10 Years & 36 & 61.1 & 0.089 \\
& $>10$ Years & 123 & 42.3 & \\
\hline Sex & Male & 101 & 44.6 & 1.114 \\
& Female & 104 & 51.9 & 0.180 \\
\hline Qualification & NCE & 48 & 54.2 & \\
& BSc & 131 & 43,5 & 5.837 \\
& MSc & 17 & 58.8 & 0.212 \\
& PhD & 1 & 0.0 & \\
\hline Locality & Other (PGDE) & 8 & 75.0 & \\
& Urban LGA & 69 & 47.8 & 0.009 \\
& Rural LGA & 136 & 48.5 & 0.521 \\
\hline
\end{tabular}

Table A.8 shows that more of the respondents in the civic education group (56.9\%) than others scored high on this issue. The Entrepreneurial group followed this with $50.8 \%$. All the same, there was no statistical difference among the different disciplinary classifications, indicating no difference among the groups, all of which contributed majorly to the high perception scores. Similarly, there were no differences in locality and school type of the respondent with regards to teachers' perception of organization of subject matter for presentation to students as a necessity. All the same, in percentage points, being fresher (beginning teachers) in the profession; in the entrepreneurial group, teaching the senior secondary students, among others contributed more to the high perception score of 3.0 point and above.

\subsection{Multivariate Logistic Regression}

Further analyses were done using perception scores on the different dependent variables captured under models 1 to 4 as categorical values (see Table A.9). The logistic regression analysis in model 1 confirmed the bivariate analysis as seen in Table A.2. Longer serving teachers in Senior Secondary Schools had higher scores than newer teachers in Junior Secondary Schools. Level and years of experience were negatively associated with perceptiveness of the teachers on organizing subject matters for presentation to the students. In other words, being a teacher in the JSS level is negatively associated with making high perception scores on organizing subject for presentation to students.

Table A.9: Multivariate Logistic Regression of the Demographic and Cognitive Characteristics of Respondents on Perception Scores on Organizing Subject Matter (Model 1); Students' Practice (Model 2); Students' Curriculum (Model 3), and Giving Support for Effective Curriculum Implementation (Model 4)

\begin{tabular}{|c|c|c|c|c|c|c|c|c|}
\hline \multirow{2}{*}{ Demographic and Cognitive Characteristics } & \multicolumn{2}{|c|}{ Model 1} & \multicolumn{2}{|c|}{ Model 2} & \multicolumn{2}{|c|}{ Model 3} & \multicolumn{2}{|c|}{ Model 4} \\
\hline & B & S.E. & B & S.E. & B & S.E. & B & S.E. \\
\hline Civic Education & -.542 & .483 & .060 & .428 & -.139 & .420 & .858 & .428 \\
\hline Entrepreneurship & -.916 & *.475 & .040 & .426 & -.046 & **.414 & .450 & .420 \\
\hline Culture \& Creative Arts & -.559 & .512 & .698 & .489 & .443 & .453 & 116 & .458 \\
\hline Locality (being in urban LGA & .011 & .359 & .181 & .337 & .401 & .326 & .084 & .328 \\
\hline Sex (being male) & -.629 & .341 & .216 & .323 & -.423 & .307 & -260 & .310 \\
\hline Level (being in JSS) & -.857 & **.334 & -.320 & .318 & -.457 & .310 & -384 & .310 \\
\hline Type of school (being in Public school) & -1.173 & 1.143 & -1.303 & 1.105 & .309 & .787 & .952 & .867 \\
\hline Year of experience (being 0-10 years) & -.836 & **.334 & .674 & .330 & .548 & .311 & .734 & .315 \\
\hline Constant & 3.472 & 1.267 & 1.414 & 1.167 & -.337 & .879 & -1.420 & .961 \\
\hline
\end{tabular}

The logistic regression analysis in model 2 confirmed the bivariate analysis as seen in Table A.4. There were no statistically significant differences in the different classification groupings. Knowledge of any of the groups did not influence perception significantly. All the same being new in the profession had significant positive impact on the perception score on organizing students' practice of the intellectual modes and abilities. Longer serving teachers in 
Senior Secondary Schools had higher scores than newer teachers in Junior Secondary Schools. Level and years of experience were negatively associated with perceptiveness of the teachers on organizing subject matters for presentation to the students. In other words, being a teacher in the JSS level is negatively associated with making high perception scores on organizing subject for presentation to students.

The logistic regression analysis confirmed the bivariate analysis as seen in Table A.6. There were no statistically significant differences in the different classification groupings. Knowledge of any of the groups did not influence perception significantly. All the same being new in the profession had significant positive impact on the perception score on organizing students' practice of the intellectual modes and anilities. Longer serving teachers in Senior Secondary Schools had higher scores than newer teachers in Junior Secondary Schools. Being a teacher in the JSS level in negatively associated with making high perception scores on organizing subject for presentation to students.

The logistic regression analysis confirmed the bivariate analysis as seen in Table A.8. However, after controlling for confounders, civic education was found to be positively associated with perception score on support for effective curriculum implementation and evaluation. Similarly, years of experience was found to be positively associated with perception score on giving support for effective curriculum implementation and evaluation.

\subsection{Opinion on the new curriculum}

Figure 1 revealed the teachers' opinion on the quality of the new curriculum design. For instance, it showed that while the fact that the new curriculum helps teachers to be more effective is the greatest strength (56.7\%), the weakest point of the new curriculum is the dearth of literature to back up its implementation (59.3\%). The resepondents also indicated the signs of a good curriculum. See details in Figure 1.

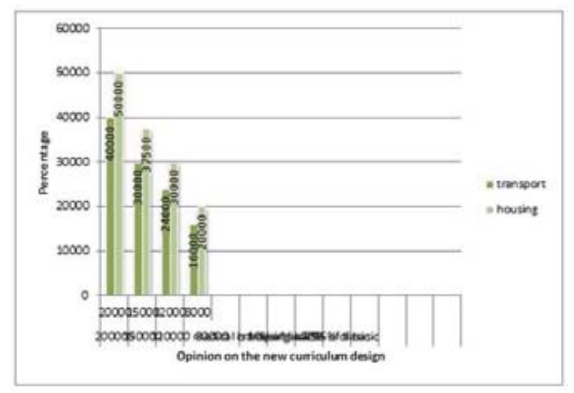

Figure 1: Teachers' Opinion on the New Curriculum Design

\section{Discussion}

The first thing to note here is that teachers' view from the government perspective on curriculum reform and policy implemented in Nigeria has not been positive. However, the current trend in teacher perception of curriculum innovations shows that teachers accept the need for these curricular innovations and in most cases agree that they implement the components of these curriculum as reflected in their response to the different components of the survey instrument, yet, student overall performance continues to decline across grade levels in the secondary level culminating in an abysmal performance in the summative assessment administered at the end of secondary education. So many factors could be attributed to these decline in student overall performance, however, teacher quality and teacher perception of efficacy are critical components for increasing student overall achievement across subject areas.

Secondly, data from the survey instrument as it relates to teacher perception on organizing subject matter for presentation to students shows that most respondents agreed strongly with the prompt, however, a small proportions of the respondent seem to only agree or even disagree with each of the prompts on this issue (details are contained in Table A.2). It is worthy to note that the distribution of respondents that agree or disagree cut across the year of experience but with a majority in the range of beginning teachers to the profession. Their responses can be attributed to so many factors including inexperience, teaching several grade levels, subject matter competence concerns, and the absence of a structured mentoring programme for new teachers in their education zone or the state for that matter. In also discussing the response of participants to the prompt on teacher perception score on organizing students' practice of 
the intellectual modes and abilities shows similarity for beginning teachers to the profession implying a significantly positive impact on the perception score. Data revealed that longer serving teachers in Senior Secondary Schools had higher scores than newer teachers in Junior Secondary Schools. Level and years of experience were negatively associated with perceptiveness of the teachers on organizing subject matters for presentation to the students. In other words, being a teacher in the JSS level is negatively associated with making high perception scores on organizing subject for presentation to students (See Table A.7).

Thirdly, eighty two percent of respondents seem to strongly agree to 'ensuring that their students are active during learning', yet only fifty three percent of them strongly agree to varying the instructional context to provide multiple opportunities for mastery of leading objectives. More interesting is that slightly over $50 \%$ of respondents who strongly agreed to ensuring students are active during learning, strongly agreed to pacing their students' work based on feedback (See Table A.8). In order words formative assessment was not an integral component of curriculum delivery. The spread of respondents to this key aspect of curriculum innovation implementation was not based on demographic and cognitive factors. Also, there was no significant difference in the perception of beginning and experienced teachers to this component of the survey. In the same table, respondents were also showed a difference in the percentage of teachers in the motivation component. Although seventy- one percent strongly agree that they encourage students to cultivate the desired behavior for lifelong learning, less than $57 \%$ strongly agree that they show students the value of learning the concepts and principles to be taught (in the subject) by demonstrating its relevance to meaningful work. This response did not reflect demographic and cognitive factors and shows that perception of motivation within curriculum may vary based on different levels of teacher appreciation of the implications of motivation to effective implementation of any curriculum innovation.

Lastly, results from the open ended responses showed that teachers in the study have been working under great pressure. A good number of them have been concerned about their capacity to carry on with the different government interventions referred to as innovations in curriculum and the continued low overall achievement of students. Under the new curriculum innovation approach of the federal government to introduce four new subject areas without targeted training and sufficient materials, teachers feel subjected to undue pressure without prerequisite support. Interesting though is the response to Table 11 where only fifty five percent of respondents across demographic and cognitive levels strongly agree that curriculum materials be made available so that teachers can become acquainted with the new materials and methods before advocating for use by responsible authorities (private and public), yet approximately $36 \%$ of the same group of respondents strongly agree that teachers should be given opportunity to work together with other teachers in the same grade level to support teaching efficiency and professional growth. This response may have resulted from the almost non-existent structured mentoring culture that exposes beginning teachers and their mentors to the benefits of collaborative learning. The development of peer thinking and sharing skills will also impact differently teacher appreciation of role in improving curriculum implementation and student overall achievement. Darling-Hammond (1999) as cited in Williams (2011), noted that there is currently significant body of literature exhorting the advantages of professional learning in collegial communities within authentic context of schools in which teachers work. Furthermore, teacher targeted professional development based on numerous studies is an essential component for successfully implementing any innovation in curriculum in Enugu State and anywhere for that matter (Blank et al 2008; Borko, 2004; Darling-Hammond et al 2009; Garet et al 1999). Data from Table 11 shows that about $78 \%$ of respondents across demographic or cognitive levels agree that they will be more effective as teachers if the authorities provide targeted professional growth.

\section{Conclusions}

The study has revealed how teacher perception of curriculum can influence the effective implementation of policies intended to foster innovation in curriculum in Nigeria. In the study, we discovered that teachers in Enugu State of Southeast Nigeria. Curriculum policies implemented in the past two decades by the federal and state governments of Nigeria have shown minimal success and created a level of apprehension for teachers who are tasked with the implementation of these curriculum innovations. For instance, our study discovered that a majority of the respondents feel that the intention to introduce the four new subjects; informational communication technology, entrepreneurial education, cultural and dramatic arts and civic education are needful especially as the country's economic and human quality indices continue to plummet is commendable. However, involving classroom teachers in the planning of these new curriculum and creating clusters of content specialists within education zones in the states and the geopolitical zones will help in increasing teacher buy-in and increase the chances of effective implementation. We must point out that a common consensus among teachers who participated in the study is that teachers are weighed down by implementing the various 
innovations adopted in their schools, and the policy seems to have resulted in enlarged hindrance for teachers especially as it concerns their work. It becomes important that the relevant government agencies, State Ministries of Education and policy makers reconsiders how the curriculum can be tailored into school and classroom truth in order to safeguard the successful implementation to achieve improved performance in the Nigerian school system.

This study did not just contribute to the curriculum implementation and innovation literature in general but it also made a major contribution to what has been, until now, a limited body of research reporting teachers' perception of their knowledge and understanding of curriculum implementation when developing nations develop policies that are termed as innovation in their school system. The evidence from the study is convincing that curriculum implementation phases can help teacher efficacy and students overall achievement. In addition, teacher perception of targeted professional development and other resource support from government can increase performance and lead to the successful implementation of new innovations integrated into current curricular framework in the Nigerian secondary education.

\section{References}

Anderson, R. D., (1996). Study of curriculum reform. Washington DC: U.S. Government Printing Office.

Blank, R.K., de las Alas, N., \& Smith, C., (2008). Does teacher professional development have effects on teaching and learning? Evaluation findings from programs in 14 states.

Retrieved from Council of Chief State School Officers website: Available at http://www.ccsso.org/documents/2008/does_teacher_ professional_development_2008.pdf. (October 23, 2012)

Borko, H., (2004). Professional development and teacher learning: Mapping the terrain. Educational Researcher, Vol 33 (8), pp 3-15.

Charalambous. C.Y. \& Philippou. G.N., 2010. Teachers' concerns and efficacy beliefs about implementing a mathematics curriculum reform: integrating two lines of inquiry. Educ Stud Math Vol.75 pp. 1-21. DOI 10.1007/s10649-010-9238-5

Cuban L., (1993). How teachers taught: constancy and change in American classroom 1890-1990 (2nd ed.). New York, Teachers College Press.

Cuban, L., (1995). The hidden variable: How organizations influence teacher responses to secondary science curriculum reform. Theory into Practice, Vol 34, pp.4-11.

Creswell, J., (2003). Research design. Qualitative, quantitative and mixed methods approaches. Thousand Oaks, CA: Sage.

Darling-Hammond, L., Wei, R.C., Andree, A., Richardson, N., \& Orphanos, S., (2009). Professional learning in the learning profession: A Status report on teacher development in the United States and abroad. Washington, DC: National Staff Development Council.

Datnow, A., Hubbard, L., \& Mehan, H., (2002). Extending educational reform: From one school to many. New York: Routledge.

Duke, D., (2004). The challenges of educational change. Boston: Allyn and Bacon.

Erickson, H.L., (2001). Stirring the head, heart and soul: Redefining curriculum and instruction (2nd ed.) Corwin Press, Inc: USA.

Fine C, Raack L. Professional Development: Changing Times. NCREL's Policy Briefs. (1994). Available at http://www.ncrel.org/sdrs/ areas/issues/envrnmnt/go/94-4over.htm. (October 23, 2012)

Flouris, G. and Pasias, G., (2003). A critical appraisal of curriculum reform in Greece (1980-2002): trends, challenges, and perspectives. European Education, Vol. 35(3), pp. 73-90.

Fullan, M., (2001). Leading in a culture of change; Jossey-Bass: San Francisco, CA.

Garret, M.S., Birman, B.F., Porter, A.C., Desimone, L. Herman, R., \& Yoon, K.S., (1999).

Designing professional development: Lessons from the Eisenhower program and technical appendices (Report No. ED/OUS99-3) Washington, DC: American Institutes for Research.

Gordon HRD, Yocke R., (1999). Relationship between personality characteristics and observable teaching effectiveness of selected beginning career and technical education teachers. Journal of Vocational and Technical Education, , 16(1). Available at http://scholar.lib.vt.edu/ejournals/JVTE/v16n1/. (October 22, 2014)

King-Sang Chan, J., (2010). Teacher' response to curriculum policy implementation: Colonial constraints for curriculum reform. Educational Research for Policy and Practice.Vol. 9 pp 93-106. DOI 10.1007/s10671-010-9082-5

Pierce AJ., (1981). Should you be putting innovations into use in your industrial arts facilities? Paper presented at the Annual Conference of the American Vocational Association, Atlanta, Geaogia..

Osborne, J., Simon, S. and Collins, S., (2003). Attitudes towards science: a review of the literature and its implications. International Journal of Science Education, Vol 25(9), pp.1049-1079.

Shao X., Bruening T. (2005). Teachers' Perception of Curriculum Reforms and Teacher Training Programs in Chinese Agricultural Schools. Spring 2005; Vol 12 (1):37-46.

Reed CJ., (2000). Teaching with power: Shared decision-making and classroom practice. New York: Teachers College, Columbia University.

Roehrig, G. H., Kruse, R.A., (2005). The Role of Teachers' Beliefs and Knowledge in the Adoption of a Reform-Based Curriculum. School Science and Mathematics, Vol. 105, Issue 8

Van driel, J.H., Bulte, A.M. and Verloop, N., (2008). Using the curriculum emphasis concept to investigate teachers' curricular beliefs in the context of educational reform. Journal of Curriculum Studies. Vol.(40)1. pp 107-122 DOI: 10.1080/00220270601078259

Williams, R., (2011). The contribution of gaining an academic qualification to teachers' professional training. Journal of Education for Teaching. Vol (37)1 pp 37-49. DOI: 10 1080/02607476.2011.538270 